\title{
Amphiphilic 3-Arm Star Block Polymers by Living Cationic Polymerization
}

\author{
Reiko TAKAHASHI, Makoto OUCHI, Kotaro SATOH, Masami KAMIGAITO, and Mitsuo SAWAMOTO ${ }^{\dagger}$
}

Department of Polymer Chemistry. Graduate School of Engineering.

Kyoto University, Kyoto 606-850I, Japan

(Received February 12, 1999)

\begin{abstract}
Via living cationic polymerization with a trifunctional initiator, amphiphilic tri-armed star block copolymers were synthesized, where each arm consisted of an AB-block copolymer with a hydrophobic and soft vinyl ether segment and a hydrophilic (amine-containing) and hard styrene segment. The sequential living polymerization was initiated first for 2-chloroethyl vinyl ether (CEVE) with the trifunctional $\mathrm{HCl}$-adduct (1) of a trivinyl ether in conjunction with $\mathrm{SnCl}_{4}$ in the presence of $n$ - $\mathrm{Bu}{ }_{4} \mathrm{NCl}$ and 2,6-ditert-butyl-4-methylpyridine (DTBMP) in $\mathrm{CH}_{2} \mathrm{Cl}_{2}$ at $-78{ }^{\circ} \mathrm{C}$, followed by block polymerization of $p$-(phthalimidemethyl)styrene (ImSt). The polymers had $3 \mathrm{arm}$ chains with controlled molecular weights and compositions and with narrow molecular weight distributions $\left(M_{w} / M_{n} \sim 1.3\right)$. Similar star amphiphiles were prepared by "one-shot" living cationic block polymerizations of CEVE and ImSt with $1 / \mathrm{SnCl}_{4} / \mathrm{DTBMP}$ in $\mathrm{CH}_{2} \mathrm{Cl}_{2}$ at $-15^{\circ} \mathrm{C}$, due to the large reactivity difference between the two monomers (CEVE $>\mathrm{ImSt}$ ). Hydrazinolysis of the imide functions gave tri-armed amphiphilic block copolymers consisting of a hydrophobic poly(CEVE) soft segment and a hydrophilic hard polystyrene segment with pendant primary amino groups, soluble in dimethyl sulfoxide, methanol, water, and $0.5 \mathrm{~N} \mathrm{HCl}$. Besides the soft-hard (CEVE-ImSt) version, the soft-soft tri-armed polymers were also prepared, consisting of an amino-functionalized hydrophilic soft poly(vinyl ether) segment and a hydrophobic poly(CEVE) segment. The surface tension of the tri-armed polymers was smaller than that of the linear block (or arm) polymers. Small angle light scattering measurement showed that these tri-armed copolymers exit as unimers in water.
\end{abstract}

KEY WORDS Living Polymerization / Cationic Polymerization / Block Copolymer / Amphiphilic Polymer / Star Polymer / Tri-Armed Polymer / Multifunctional Initiator /

One of the most useful synthetic methods of sequential block polymers is living polymerization where all the polymer chains are "alive" without suffering side reactions.' Since the discovery of living anionic polymerization, a variety of block copolymers have been synthesized, and recent efforts permitted the synthesis of block copolymers of functional monomers. ${ }^{2}$ Also, the development of living cationic polymerizations of vinyl ethers ${ }^{3}$ has opened the way for the synthesis of well-defined block copolymers as well as homopolymers with functional groups such as alcohol, amine, and carboxylic acid (Scheme 1). ${ }^{4}$
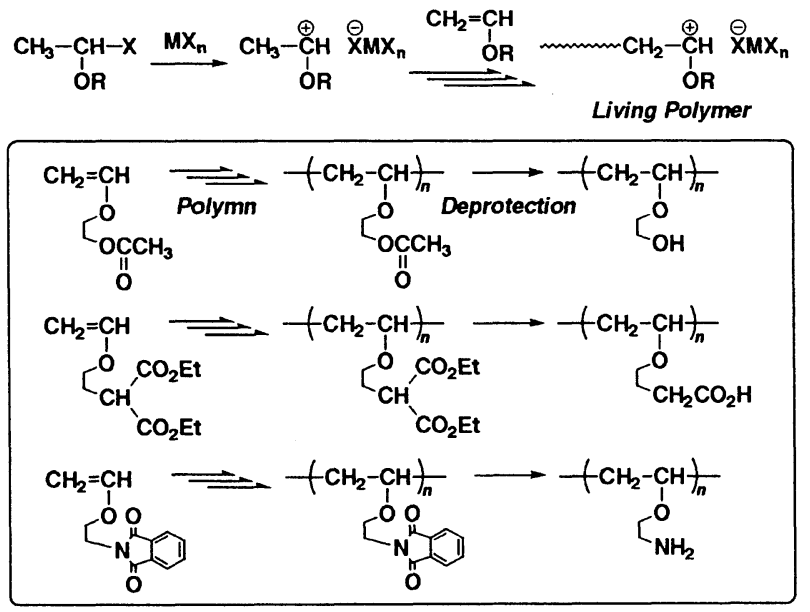

Scheme 1.

In addition to molecular weights, end-groups, etc., living polymerization can control the three-dimensional or spatial shape of polymers to give, for example, multi-armed or starshaped polymers. By our living cationic systems, we have prepared a series of multi-armed star polymers in three ways

\footnotetext{
† To whom correspondence should be addressed.
}

(Scheme 2$):{ }^{4}$ (A) living polymerization with a multifunctional initiator; (B) quenching of living polymers with a multifunctional coupling agent (terminator); and (C) linking reactions of living polymers with divinyl compounds.

\section{(A) Multifunctional Initiator Method}

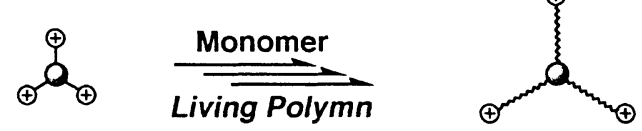

(B) Multifunctional Terminator Method

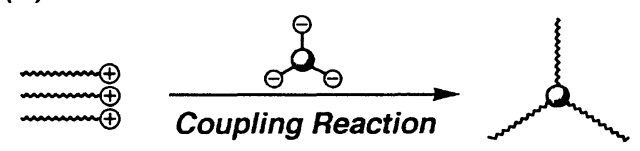

(C) Polymer Linking Method
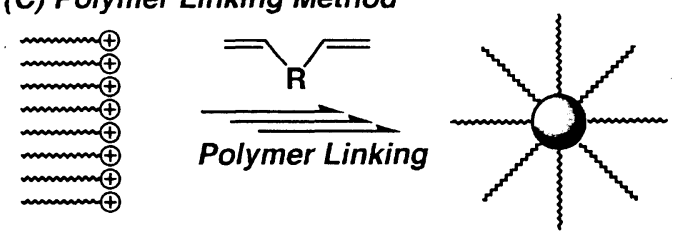

Scheme 2.

This study is to synthesize tri-armed amphiphilic block copolymers by sequential living cationic polymerization with a trifunctional initiator, the arm of which consists of hitherto unknown hydrophobic/hydrophilic segment pairs: a hydrophobic soft poly(vinyl ether) segment and a hydrophilic hard polystyrene segment (Scheme 3). A series of multi-armed amphiphilic block copolymers with both poly(vinyl ether) segments have been prepared by living cationic polymerizations $^{5-7}$ whereas there were few examples based on pairs of different kinds of monomers except for hydroxy-based tetraarmed block copolymers of vinyl ethers and $\alpha$-methylstyrene or $p$-hydroxystyrene by using a tetrafunctional quencher. ${ }^{8.9}$ 
Herein we chose 2-chloroethyl vinyl ether (CEVE) as a hydrophobic soft segment and $p$-(aminomethyl)styrene as a hydrophilic hard segment in the amphiphilic tri-armed block copolymer. The latter segment can be obtained by living cationic polymerization of $p$-(phthalimidemethyl)styrene ( $\mathrm{ImSt}$ ) with the $\mathrm{R}-\mathrm{Cl} / \mathrm{SnCl}_{4}$ initiating system in the presence of $n-\mathrm{Bu}_{4} \mathrm{NCl}$, followed by hydrazinolysis of the imide functions. ${ }^{10}$ For example, we also synthesized similar tri-armed block copolymers with a soft hydrophilic poly(vinyl ether) segment derived from poly[2-(vinyloxy)ethyl phthalimide] [poly(ImVE)] as well as their linear block copolymers. The properties of the copolymers were investigated by surface tension and small angle light scattering (SAXS) measurements, and were compared to those of the linear counterparts.

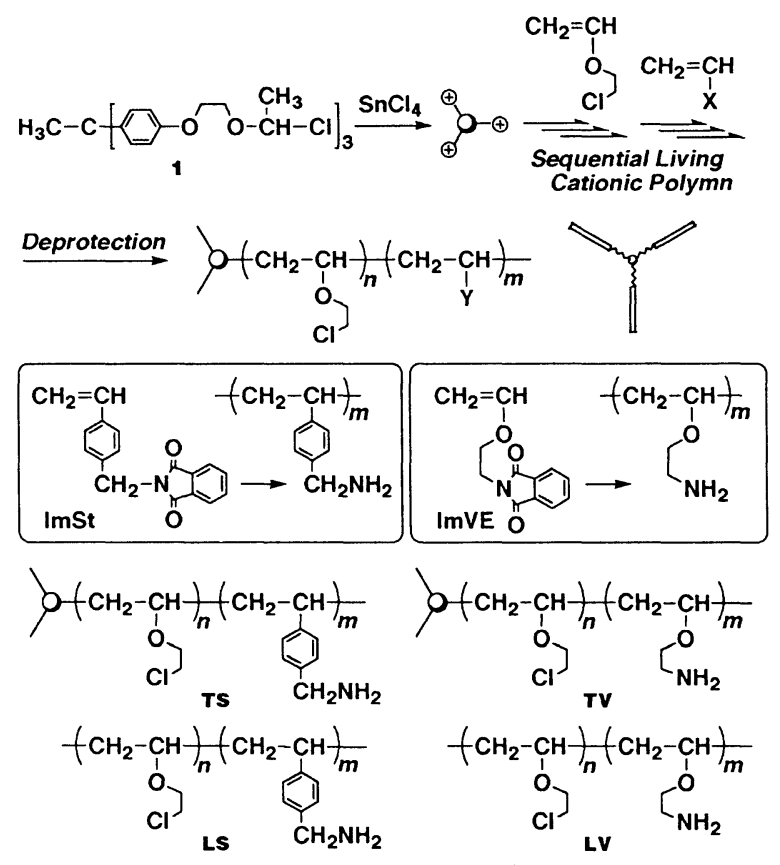

Scheme 3.

\section{EXPERIMENTAL}

\section{Materials}

2-Chloroethyl vinyl ether (Nisso Maruzen Chemical; purity $>99 \%$ ) was washed with $10 \%$ aqueous sodium hydroxide solution and then with water, dried overnight with anhydrous sodium sulfate, and distilled twice under reduced pressure over calcium hydride before use. ImVE was prepared by the reaction of CEVE with potassium phthalimide and purified as reported. ${ }^{11} \mathrm{SnCl}_{4}$ (Aldrich, $1.0 \mathrm{M}$ solution in $\mathrm{CH}_{2} \mathrm{Cl}_{2}$ ), $n-\mathrm{Bu}_{4} \mathrm{NCl}$ (Tokyo Kasei; purity $>98 \%$ ), and 2,6di-tert-butyl-4-methylpyridine (DTBMP; Aldrich; purity $>99 \%$ ) was used as received. $\mathrm{CH}_{2} \mathrm{Cl}_{2}$ (Wako Chemicals; HPLC grade; purity $>99 \%$ ) was dried overnight with calcium chloride and doubly distilled over phosphorous pentoxide and then calcium hydride before use. Chlorobenzene and 1,2-dibromobenzene (gas-chromatographic internal standards) were doubly distilled over phosphorous pentoxide under reduced pressure before use. A monofunctional initiator, the $\mathrm{HCl}$-adduct of CEVE, was prepared as reported. ${ }^{12}$

\section{Synthesis of ImSt}

The imide-functionalized styrene was prepared by the re- action of $p$-(chloromethyl)styrene (CMSt; Seimi Chemical; $>95 \%$ para) with potassium phthalimide. ${ }^{10}$ In a $500 \mathrm{~mL}$, three-necked, round-bottom flask fitted with a reflux condenser, a thermometer, and a magnetic stirrer were charged potassium phthalimide $(50 \mathrm{~g}, 0.27 \mathrm{~mol}), n-\mathrm{Bu}_{4} \mathrm{NBr}(1 \mathrm{~g})$ as a phase-transfer catalyst, and $N, N$-dimethylformamide (DMF; $150 \mathrm{~mL}$ ). Into the heterogeneous solution was added CMSt $(35 \mathrm{~mL}, 0.25 \mathrm{~mol})$ via a syringe, leading to heat evolution. The mixture was stirred at room temperature for $3 \mathrm{~h}$, diluted with $200 \mathrm{~mL}$ chloroform, and then filtered to remove the precipitated $\mathrm{KCl}$. The solution was washed with $10 \%$ sodium hydroxide solution and water. The organic layer was evaporated to give the phthalimide monomer as a white yellow solid (yield $=95 \%$ ). The crude product was recrystallized from toluene to give ImSt as a white crystal (isolated yield $=59 \%$ from CMSt), identified by ${ }^{1} \mathrm{H}$ and ${ }^{13} \mathrm{C}$ NMR.

\section{Synthesis of Trifunctional Initiator (1)}

The trifunctional initiator (1) was synthesized by bubbling dry $\mathrm{HCl}$ gas through a solution of a trivinyl ether $\left[\mathrm{CH}_{3} \mathrm{C}\right.$ $\left.\left(\mathrm{C}_{6} \mathrm{H}_{5}-p-\mathrm{OCH}_{2} \mathrm{CH}_{2} \mathrm{OCH}=\mathrm{CH}_{2}\right)_{3}\right]^{13}$ (in $30 \mathrm{~mL}$ of $\mathrm{CH}_{2} \mathrm{Cl}_{2} ; 200$ $\mathrm{mM}$ ) for $1 \mathrm{~h}$ at $-78{ }^{\circ} \mathrm{C}$; the gas was generated by dropping concentrated sulfuric acid into powdery sodium chloride and subsequently dried by passing it thorough a column packed with calcium chloride. The excess $\mathrm{HCl}$ gas in the reaction mixture was removed by bubbling dry nitrogen for $30 \mathrm{~min}$ at $-78{ }^{\circ} \mathrm{C}$ and for an additional $30 \mathrm{~min}$ at $0{ }^{\circ} \mathrm{C}$. The clean and quantitative formation of 1 was confirmed by ${ }^{1} \mathrm{H}$ NMR. The solution was sealed into ampules under dry nitrogen and stored in a freezer at $-70^{\circ} \mathrm{C}$. The concentration of 1 in the stock solution was measured by ${ }^{\prime} \mathrm{H}$ NMR with $n-\mathrm{Bu}_{4} \mathrm{NCl}$ as the internal standard; an acetone- $d_{6}$ capillary tube was used for the external lock signal.

\section{Polymerization Procedures}

Polymerization was carried out under dry nitrogen in baked glass tubes equipped with a three-way stopcock and a magnetic stirrer. A typical example for the synthesis of triarmed block copolymers of CEVE and ImSt (TS in Scheme 3 ) is given below: The reaction was initiated by adding, via dry syringes under stirring, solutions of $1(100 \mathrm{mM}$ in $\left.\mathrm{CH}_{2} \mathrm{Cl}_{2}, 0.90 \mathrm{~mL}\right)$ and a mixture of $\mathrm{SnCl}_{4}$ and $n-\mathrm{Bu}_{4} \mathrm{NCl}(200$ $\mathrm{mM}$ and $180 \mathrm{mM}$, respectively, in $\mathrm{CH}_{2} \mathrm{Cl}_{2}, 0.90 \mathrm{~mL}$ ) sequentially in this order into a mixture $(7.2 \mathrm{~mL})$ of CEVE (0.41 $\mathrm{mL})$, chlorobenzene $(0.41 \mathrm{~mL})$, and DTBMP (18 mmol) in $\mathrm{CH}_{2} \mathrm{Cl}_{2}$ at $-78{ }^{\circ} \mathrm{C}$. After 15 min $(95 \%$ conversion of CEVE), a mixture $(6.0 \mathrm{~mL})$ of $\operatorname{ImSt}(2.13 \mathrm{~g}), 1,2-$ dibromobenzene $(0.43 \mathrm{~mL})$, DTBMP $(162 \mathrm{mmol})$ in $\mathrm{CH}_{2} \mathrm{Cl}_{2}$ and then $1.0 \mathrm{M} \mathrm{SnCl}_{4}$ solution $(1.62 \mathrm{~mL})$ in $\mathrm{CH}_{2} \mathrm{Cl}_{2}$ were added to the preformed living poly(CEVE) solution. The solution was stirred at $-78^{\circ} \mathrm{C}$ for $15 \mathrm{~min}$ after the addition of $\mathrm{SnCl}_{4}$. It was then warmed to $-15{ }^{\circ} \mathrm{C}$ and quenched with methanol $(6 \mathrm{~mL})$ after an additional $100 \mathrm{~h}$. Monomer conversions were determined by gas chromatography with chlorobenzene and 1,2-dibromobenzene as internal standards for CEVE and ImSt, respectively.

The quenched reaction mixture was diluted with $\mathrm{CH}_{2} \mathrm{Cl}_{2}$ $(30 \mathrm{~mL})$, washed sequentially with $2 \%$ hydrochloric acid, aqueous $1 \%$ sodium hydroxide solution, and water to remove the tin-containing residues, evaporated to dryness under reduced pressure, and dried in vacuo overnight to give the product polymers. 
Hydrazinolysis of Block Copolymers

A typical example is shown below: Before the deprotection, the recovered polymers were precipitated in methanol twice to remove low molecular weight compounds such as residual ImSt. A sample of the precipitated polymer $(1.71 \mathrm{~g})$ was dissolved in a 1,4-dioxane/methanol $(100 / 50 \mathrm{~mL})$ mixture, and hydrazine hydrate ( 10 equiv. to the imide functions in the polymer) was added. The solution was magnetically stirred at $75^{\circ} \mathrm{C}$ for $3 \mathrm{~h}$. After addition of $5 \mathrm{~N} \mathrm{HCl}(10.5 \mathrm{~mL} ; 10$ equiv. to the imide functions) to the turbid solution, it was purified by dialysis (Spectra/Por 7, molecular weight cutoff ca. 1000). Water was evaporated from the dialyzed mixture to give the amino-functionalized block copolymers. The deprotection of the phthalimide groups was confirmed by ${ }^{1} \mathrm{H}$ NMR. The sample was freeze-dried in the presence of a small amount of $\mathrm{CF}_{3} \mathrm{CO}_{2} \mathrm{H}$ for further analysis.

\section{Measurements}

The molecular weight distribution (MWD), numberaverage molecular weight $\left(M_{n}\right)$, and polydispersity ratio $\left(M_{w} / M_{n}\right)$ of the polymers were measured by size-exclusion chromatography (SEC) in chloroform at $40{ }^{\circ} \mathrm{C}$ on three polystyrene gel columns (Shodex K-805L $\times 3$ ) that were connected to a Jasco PU-980 precision pump and a Jasco 930-RI refractive index and 970-UV ultraviolet detectors. The columns were calibrated against 11 standard polystyrene samples (Pressure Chemicals; $M_{n}=580-1547000 ; M_{w} / M_{n} \leq 1.1$ ) as well as the monomer. ' $\mathrm{H}$ NMR spectra were recorded in $\mathrm{CDCl}_{3}$ at $25{ }^{\circ} \mathrm{C}$ on a JEOL JNM-LA500 or GSX-270 spectrometer, operating at 500.2 or $270.7 \mathrm{MHz}$, respectively. Polymers for ${ }^{1} \mathrm{H}$ NMR analysis were fractionated by preparative SEC (column: Shodex K-2002). Surface tension was measured at room temperature by an Automatic Surface Tensiometer (CBVP-Z, Kyowa Interface Science) with the Wilhelmy plate. SAXS measurements were performed on a Kratky type camera (Rigaku Corporation) equipped with a rotating anode X-ray generator and a position sensitive proportional counter (PSPC). The SAXS instrument has been described in detail elsewhere. ${ }^{14}$ Sample solutions were measured in glass capillaries (Mark, Berlin) with a diameter of $2 \mathrm{~mm}$.

\section{RESULTS AND DISCUSSION}

\section{Living Polymerization of CEVE with 1}

Polymerization of CEVE was carried out with the $1 / \mathrm{SnCl}_{4}$ initiating system in the presence of $n-\mathrm{Bu}_{4} \mathrm{NCl}$ in $\mathrm{CH}_{2} \mathrm{Cl}_{2}$ at $-78{ }^{\circ} \mathrm{C}\left([\mathrm{CEVE}]_{0} /[1]_{0} /\left[\mathrm{SnCl}_{4}\right]_{0} /\left[n-\mathrm{Bu}_{4} \mathrm{NCl}\right]_{0}=500 / 10 / 20 / 20\right.$ $\mathrm{mM}){ }^{4}$ The polymerization occurred smoothly without an induction phase to reach $100 \%$ conversion in $1 \mathrm{~h}$. Figure 1 shows the $M_{n}, M_{11} / M_{n}$, and MWD of the obtained polymers. The MWDs were narrow throughout the reaction $\left(M_{w} / M_{n}<\right.$ 1.2). The $M_{n}$ increased in direct proportion to monomer conversion and agreed well with the calculated values assuming that one molecule of 1 generates one molecule of polymers. Thus, living polymerization of $\mathrm{CEVE}$ was achieved with 1 when coupled with $\mathrm{SnCl}_{4}$ and $n-\mathrm{Bu}_{4} \mathrm{NCl}$.

Figure 2 shows the ' $\mathrm{H}$ NMR spectrum of the obtained polymer. In addition to the large absorptions of the mainchain repeat units $(h-k)$, there can be seen the signals of aromatic protons ( $b$ and $c$ ) originated from 1 and terminal methine $(l)$ and methoxy $(m)$ protons due to quenching with

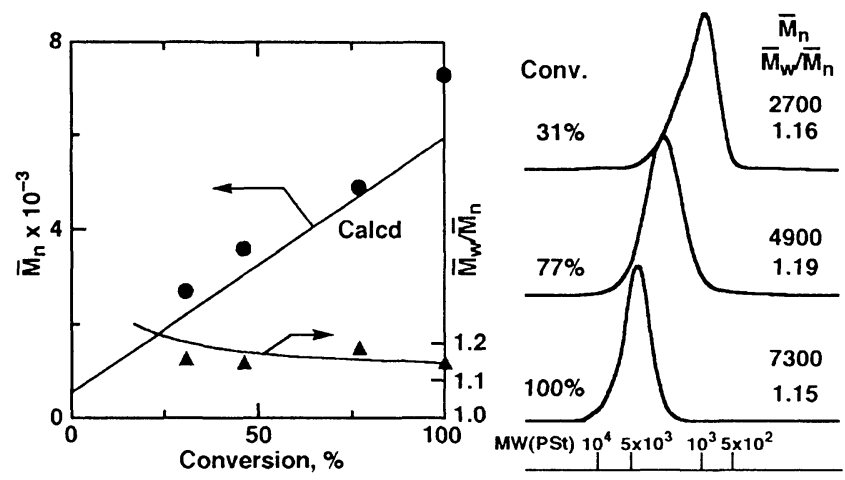

Figure 1. $M_{n}, M_{11} / M_{n}$, and MWD curves of poly(CEVE) obtained with $1 / \mathrm{SnCl}_{4} / n-\mathrm{Bu}_{4} \mathrm{NCl}$ in $\mathrm{CH}_{2} \mathrm{Cl}_{2}$ at $-78{ }^{\circ} \mathrm{C}:[\mathrm{CEVE}]_{0} /[1]_{0} /\left[\mathrm{SnCl}_{4}\right]_{0} /[n-$ $\mathrm{Bu}_{4} \mathrm{NCl}_{0}=500 / 10 / 20 / 20 \mathrm{mM}$.

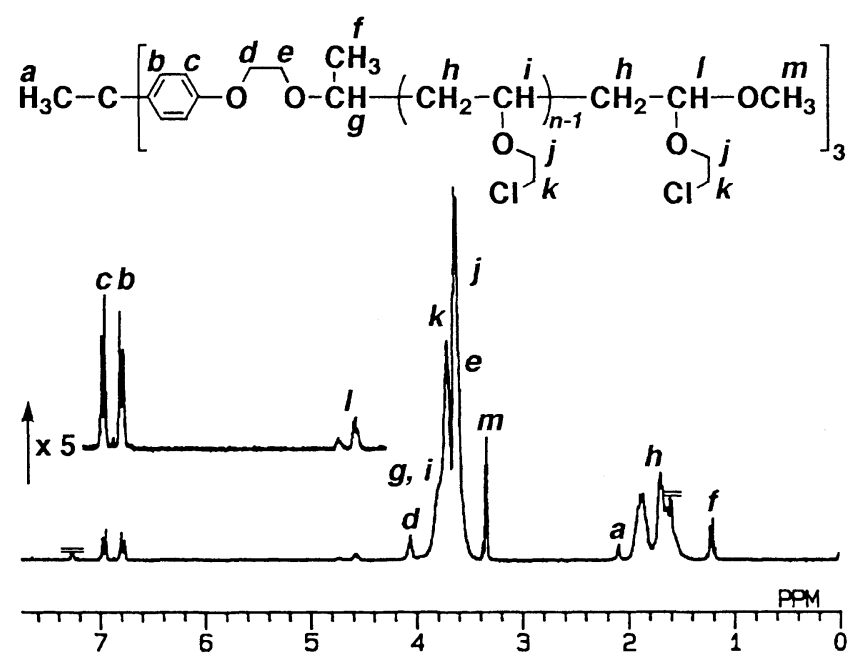

Figure 2. ${ }^{1} \mathrm{H}$ NMR spectrum of poly (CEVE) obtained with $1 / \mathrm{SnCl}_{4} / n$ $\mathrm{Bu}_{4} \mathrm{NCl}$ in $\mathrm{CH}_{2} \mathrm{Cl}_{2}$ at $-78{ }^{\circ} \mathrm{C}:[\mathrm{CEVE}]_{0} /[1]_{0} /\left[\mathrm{SnCl}_{4}\right]_{0} /\left[n-\mathrm{Bu}_{4} \mathrm{NCl}\right]_{0}=$ $500 / 10 / 20 / 20 \mathrm{mM}$. $M_{n}(\mathrm{SEC})=7300, M_{n}(\mathrm{NMR})=7400, F_{n}=3.0$.

methanol. The $M_{n}(\mathrm{NMR})$ obtained from the main chain protons $(i-k)$ and the aromatic protons $(b$ and $c$ ) is 7400 , which is in good agreement with those based on SEC, 7300. The arm number $\left(F_{n}\right)$ of the polymers, obtained from the peak intensity ratio of terminal methine proton $(l)$ to the core aromatic protons $(b$ and $c$ ), was 3.0. These results indicate that the initiator 1 affords tri-armed living poly(CEVE).

\section{Block Copolymerization of CEVE and ImSt with 1}

Sequential block copolymerization of ImSt from the triarmed living poly(CEVE) was then examined with the use of $1 / \mathrm{SnCl}_{4} / n-\mathrm{Bu}_{4} \mathrm{NCl}$ in $\mathrm{CH}_{2} \mathrm{Cl}_{2}$. On addition of an equimolar amount of ImSt into the living poly(CEVE), obtained at $-78{ }^{\circ} \mathrm{C}$, the polymerization of the second monomer was extremely slow due to its lower reactivity. We then added $\mathrm{SnCl}_{4}$ (9 times the initial amount), stirred at $-78^{\circ} \mathrm{C}$ for 15 $\mathrm{min}$, and raised the temperature to $-15^{\circ} \mathrm{C}$ to accelerate the polymerization of ImSt. The second polymerization now occurred faster to reach $92 \%$ conversion in an additional $13 \mathrm{~h}$. The SEC curve shifted to higher molecular weights with keeping its narrowness. However, there was another small low-molecular-weight peak with an UV absorption due to the formation of homopoly( $(\mathrm{mSt})$, most probably generated by chain-transfer reactions in the second-phase polymerization. 
The polymerization in the presence of DTBMP, a proton trap, was then investigated (Figure 3). DTBMP (20 mM) was added into the solution prior to the first-stage polymerization (see Experimental). Living tri-armed poly(CEVE) with narrow MWDs $\left(M_{w} / M_{n}=1.10\right)$ was obtained in the presence of the hindered pyridine, as shown in Figure $3 \mathrm{~A}$. On addition of ImSt and $\mathrm{SnCl}_{4}$ followed by warming the reaction mixture to $-15{ }^{\circ} \mathrm{C}$, ImSt was polymerized to give block polymers with narrow and monomodal MWDs $\left(M_{w} / M_{n}\right.$ $=1.28$ ). Similarly, another block copolymer with CEVE/ $\operatorname{ImSt}=1 / 2$ unit ratio was also prepared (Figure $3 \mathrm{~B}$ ). ${ }^{1} \mathrm{H}$ NMR analysis of the latter copolymer showed that the number-average degrees of polymerizations $\left(D P_{n}\right)$ per arm were 16 for CEVE-units and 34 for ImSt-units, which were close to the calculated values 15 and 30 , respectively (see Table I below). Thus, the tri-armed block polymers of CEVE and ImSt were synthesized by sequential block copolymerization initiated with $1 / \mathrm{SnCl}_{4}$ in the presence of $n-\mathrm{Bu}_{4} \mathrm{NCl}$ and DTBMP.

\section{One-Shot Block Copolymerization of CEVE and ImSt}

The large difference in reactivity between CEVE and ImSt and the feasibility of their living polymerizations with the same initiating system prompted us to examine "one-shot" 15 block living cationic copolymerization of the two monomers. For this, into the mixture of CEVE and $\operatorname{ImSt}$ with 1 and DTBMP was added $\mathrm{SnCl}_{4}$ in $\mathrm{CH}_{2} \mathrm{Cl}_{2}$ at $-15{ }^{\circ} \mathrm{C}\left([\mathrm{CEVE}]_{0} /\right.$ $\left.[\mathrm{ImSt}]_{0} /[1]_{0} /\left[\mathrm{SnCl}_{4}\right]_{0} /[\mathrm{DTBMP}]_{0}=500 / 500 / 10 / 200 / 20 \mathrm{mM}\right)$. CEVE was consumed immediately within $10 \mathrm{sec}$, while the conversion of ImSt was 7\% (Figure 4). The obtained polymers had narrow MWDs $\left(M_{n} / M_{n}=1.23\right)$ and were triarmed poly(CEVE) with nearly one ImSt unit at the $\omega$-ends (by 'H NMR). After the consumption of CEVE, polymerization of ImSt occurred smoothly $(91 \%$ in $14 \mathrm{~h})$ to give block polymers with narrow MWDs $\left(M_{n} / M_{n}=1.23\right)$. This indicates that the block copolymers can also be obtained by sequentially polymerizing the two monomers that are fed together in the initial reaction mixture. This is the first example of one-shot block living cationic polymerization of vinyl monomers.

\section{Hydrazinolysis of Tri-Armed Block Copoly(CEVE-ImSt)}

The pendant phthalimide groups of the block copolymers were converted into primary amino functions by treating with hydrazine in a 1,4-dioxane/methanol mixture (see Experimental). Figure 5 compares the 'H NMR spectra of the triarmed block copolymers with the 1/2-unit ratio of CEVE/ ImSt (see Figure 3B) and its hydrazinolysis product, TS. Complete conversion of the imide groups into the corresponding primary amines was confirmed by the disappearance of the aromatic protons of the phthalimide moiety $(i)$. The methylene protons adjacent to the nitrogen $(h)$ also shifed upfield from $4.7 \mathrm{ppm}$ to $4.0 \mathrm{ppm}\left(h^{\prime}\right)$ on the deprotection.

The polymers after hydrazinolysis were soluble in $\mathrm{DMF}$, dimethylsulfoxide (DMSO), $\mathrm{MeOH}$, water, and $0.5 \mathrm{~N} \mathrm{HCl}$, which suggests the formation of amphiphilic block copolymers. Figure 6 shows ${ }^{1} \mathrm{H}$ NMR spectra of TS in various solvents. Irrespective of the solvents, the spectra showed the absorptions of the two segments, although there were some differences in the shape of each signal. For example, the spectrum in DMF- $d_{6}(\mathrm{~A})$ showed broad signals $\left(h^{\prime}\right)$ of the

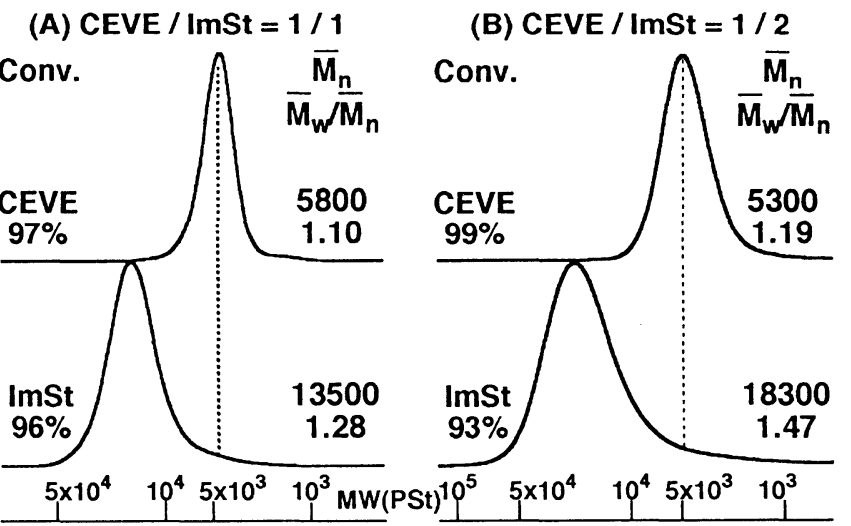

Figure 3. Block copolymerization of CEVE and $\mathrm{ImSt}$ with $1 / \mathrm{SnCl}_{4} / n$ $\mathrm{Bu}_{4} \mathrm{NCl} / \mathrm{DTBMP}$ in $\mathrm{CH}_{2} \mathrm{Cl}_{2}$ : (A) $[\mathrm{CEVE}]_{0} /[1]_{0} /\left[\mathrm{SnCl}_{4}\right]_{0} /\left[n-\mathrm{Bu}_{4} \mathrm{NCl}\right]_{0} /$ $\left[\mathrm{DTBMP}_{0}=500 / 10 / 20 / 20 / 20 \mathrm{mM} ; \mathrm{CEVE}_{0} / \mathrm{ImSt}_{\mathrm{add}}=1 / 1, \mathrm{SnCl}_{4,0}\right.$ $\mathrm{SnCl}_{4 . \text { add }}=1 / 9$. (B) $[\mathrm{CEVE}]_{0} /[1]_{0} /\left[\mathrm{SnCl}_{4}\right]_{0} /\left[n-\mathrm{Bu}_{4} \mathrm{NCl}_{0} /[\mathrm{DTBMP}]_{0}=\right.$ $450 / 10 / 20 / 18 / 2.0 \mathrm{mM} ; \mathrm{CEVE}_{0} / \mathrm{ImSt}_{\text {add }}=1 / 2, \mathrm{SnCl}_{4,0} / \mathrm{SnCl}_{4, \text { add }}=1 / 10$.
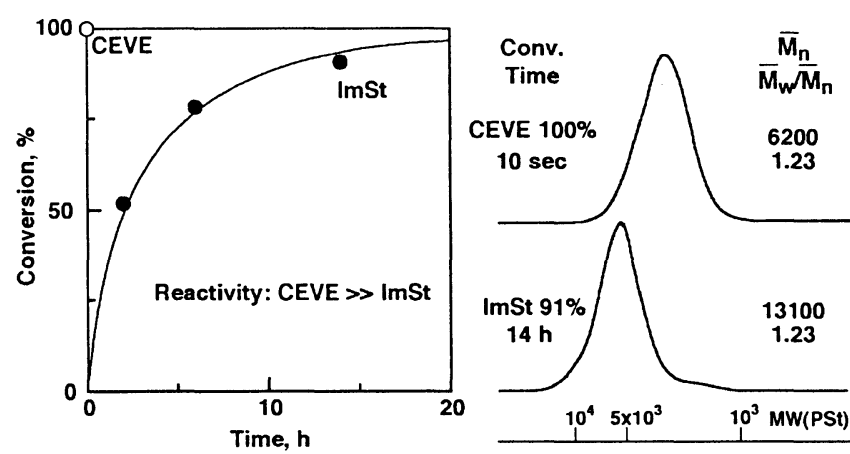

Figure 4. One-shot block copolymerization of CEVE and ImSt with $1 / \mathrm{SnCl}_{4} / \mathrm{DTBMP}$ in $\mathrm{CH}_{2} \mathrm{Cl}_{2}$ at $-15^{\circ} \mathrm{C}$ : [CEVE $]_{0} /[\mathrm{ImSt}]_{0} /[1]_{0} /\left[\mathrm{SnCl}_{4}\right]_{0} /$ $[\text { DTBMP }]_{0}=500 / 500 / 10 / 200 / 20 \mathrm{mM}$.

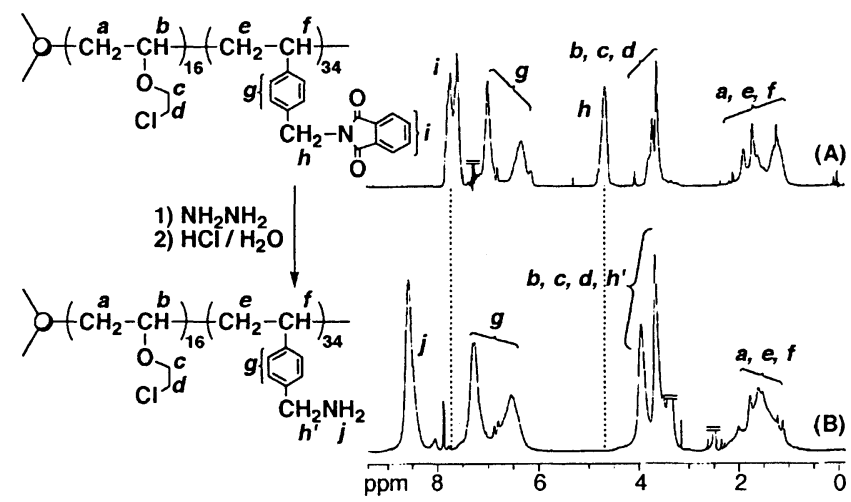

Figure 5. 'H NMR spectra of tri-armed block copoly(CEVE-ImSt) before $(\mathrm{A})$ and after $(\mathrm{B})$ hydrazinolysis: $(\mathrm{A})$ in $\mathrm{CDCl}_{3} ;(\mathrm{B})$ in DMSO- $d_{6}$.

hydrophilic $p$-(aminomethyl)styrene segment and sharp peaks $(b-d)$ of the hydrophobic CEVE segment, whereas in $\mathrm{D}_{2} \mathrm{O}$ (D) signal $h^{\prime}$ alone became sharper. These spectral changes suggest that the amphiphilic nature of the copolymer is due to the hydrophilicity of the styrene segment and the hydrophobicity of the vinyl ether segment. We also hydrazinolyzed the tri-armed block copolymers with the $1 / 1$ unit ratio of CEVE/ImSt (see Figure $3 \mathrm{~A}$ ), but the resultant polymers were less soluble in water probably due to lower contents of the hydrophilic units. 


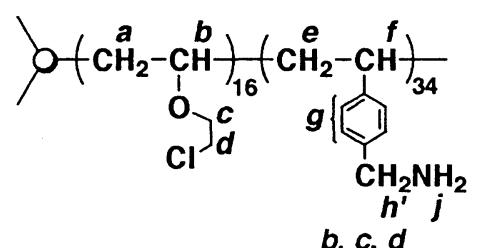

(A)
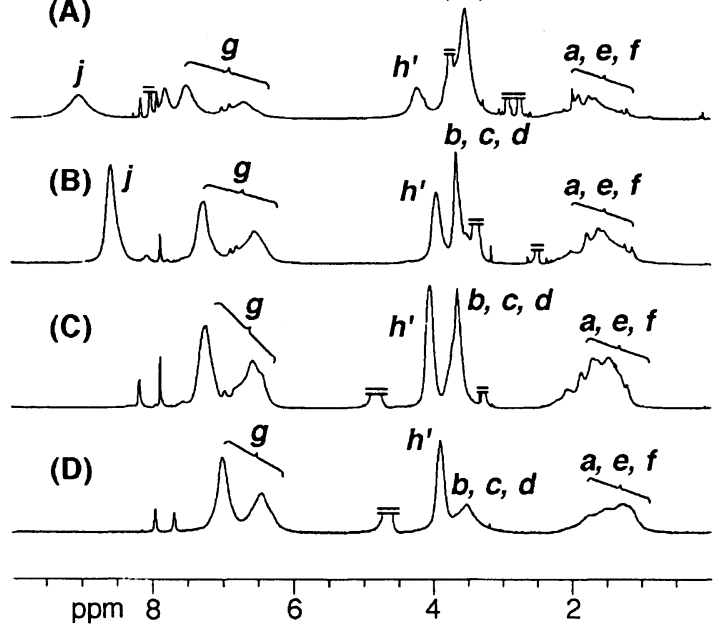

Figure 6. ' $\mathrm{H}$ NMR spectra of TS in various solvents: (A) DMF- $d_{6}$; (B) DMSO-d $d_{6}$; (C) $\mathrm{CD}_{3} \mathrm{OD}$; (D) $\mathrm{D}_{2} \mathrm{O}$.

Synthesis of Tri-Armed Block Copoly(CEVE-ImVE) and Linear Block Copolymers

The amphiphilic block copolymers (TS) thus synthesized are unique at least from two viewpoints: (1) the stiffness of the main-chain segments is different; and (2) the block copolymers are not linear but tri-armed. To know the effects of the two factors on their properties, we prepared similar triarmed block copolymers consisting of both soft vinyl ether segments (TV) as well as linear block copolymers (arm chains) with hydrophilic styrene (LS) and vinyl ether (LV) segments (see Scheme 3).

The vinyl ether-based hydrophilic segments were derived from ImVE, " similarly to the styrenic counterparts. The tri-armed block copolymers, TV, were obtained by the sequential living cationic polymerization of CEVE and ImVE with $1 / \mathrm{SnCl}_{4}$ in the presence of $n-\mathrm{Bu}_{4} \mathrm{NCl}$ and DTBMP in $\mathrm{CH}_{2} \mathrm{Cl}_{2}$ at $-78{ }^{\circ} \mathrm{C}$, followed by the hydrazinolysis of the imide pendants. The linear block copolymers were prepared with use of a monofunctional initiator (the $\mathrm{HCl}$-adduct of CEVE) in place of 1 , under otherwise the same conditions. As summarized in Table I, the produced copolymers had narrow MWDs and controlled unit numbers, $n / m$, which are close to $15 / 30$ determined by the feed ratios of the monomers to the initiators. The linear polymers had nearly one-third of tri-arms' $M_{n}$. All these block copolymers were soluble in DMSO, $\mathrm{MeOH}$, water, and $0.5 \mathrm{~N} \mathrm{HCl}$ although the solubility depends on the structures.

\section{Properties of Amphiphilic Block Copolymers}

The surface activity of a series of the amphiphilic block copolymers was measured at varying concentrations (0.0001-1 wt\%) (Figure 7). Both of the tri-armed block copolymers had higher surface tension values than the linear polymers did, which suggests that the former is difficult to form layers on surface due to their unique three-dimensional structures. Surface tension did not depend on the stiffness of the amino hydrophilic segments, because samples the
Table I. Amphiphilic block copolymers prepared by sequential living cationic polymerizations

\begin{tabular}{cccrc}
\hline Sample & $n^{\mathrm{a}}$ & $m^{\mathrm{b}}$ & $M_{n}{ }^{\mathrm{c}}$ & $M_{\mathrm{w}} / M_{n}{ }^{\mathrm{c}}$ \\
\hline TS & 16 & 34 & 18300 & 1.47 \\
LS & 17 & 34 & 6700 & 1.20 \\
TV & 18 & 32 & 15100 & 1.25 \\
LV & 19 & 37 & 6900 & 1.18 \\
\hline
\end{tabular}

${ }^{\text {a }} D P_{n}(\mathrm{NMR})$ of hydrophobic CEVE segments per arm. ${ }^{\mathrm{b}} D P_{n}(\mathrm{NMR})$ of hydrophilic amino segments per arm. ${ }^{\mathrm{c}}$ Determined from SEC before hydrazinolysis.

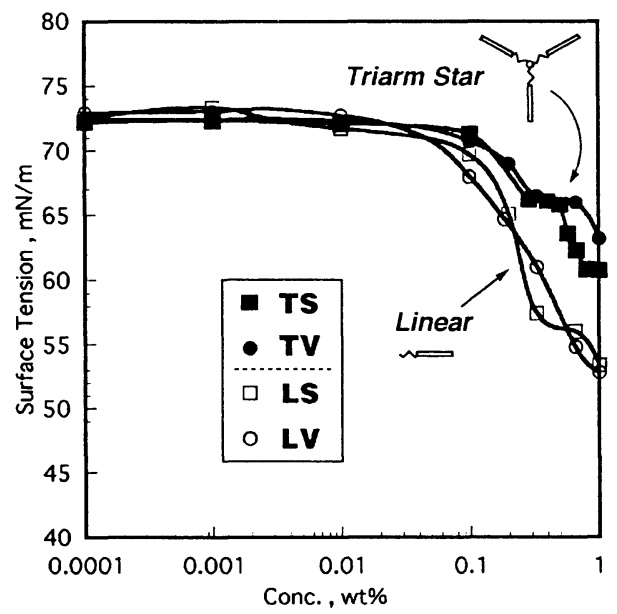

Figure 7. Surface tension of amphiphilic block polymers in aqueous solutions.

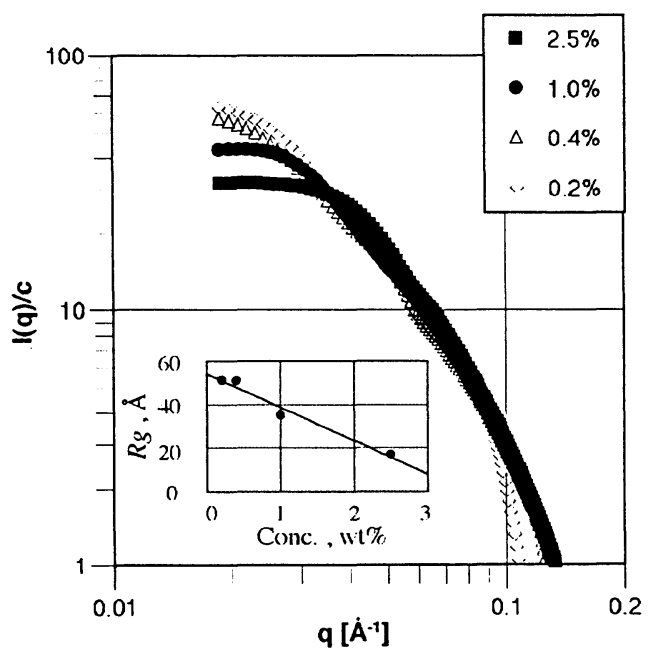

Figure 8. SAXS profiles of TS in aqueous solutions and concentration dependence of $R_{g}$ estimated by Guinier plot (inset).

styrene-based (TS) and the VE-based (TV) stars gave nearly the same profiles. All the profiles showed no critical micelle concentrations within the examined concentrations, which suggests that in aqueous solutions these amphiphilic block copolymers exist as unimers rather than micelles or aggregates.

The size and the shape of these block copolymers were analyzed by SAXS in aqueous solution. Figure 8 shows the SAXS profiles of TS at four concentrations (0.2-2.5 wt \%). The profile shape suggests that the tri-armed polymers exist 
as a unimer consistent with the surface tension measurement. The radius of gyration $\left(R_{\mathrm{g}}\right)$ of the copolymers was estimatedto be $54 \AA$ by a series of Guinier plots at different concentrations, which is also consistent with unimers rather than aggregates. Similar results were also obtained for TV and LS. In contrast, LV seems to form aggregates at higher concentrations according to the SAXS profiles. SAXS of TS were also measured in $\mathrm{HCl}$ aqueous solution, but there were almost no effects of acidity of the solutions on their sizes.

\section{CONCLUDING REMARKS}

We have synthesized novel amphiphilic tri-armed block copolymers consisting of a soft hydrophobic segment and a hard hydrophilic amine-based segment by sequential living cationic copolymerization of CEVE and ImSt with a trifunctional initiator. The copolymers had controlled molecular weights, MWDs, unit numbers, and arm numbers. Similar block copolymers with soft hydrophilic vinyl ether-based segments were obtained by the same initiating system. These tri-armed amphiphilic block copolymers existed as unimers in aqueous solutions.

Acknowledgments. The authors acknowledge Professor Hitoshi Yamaoka, Dr. Hideki Matsuoka, and Dr. Minoru Nakano of Kyoto University for their guidance in the surface tension and SAXS measurements. This work was supported by the Grant-in-Aid for Scientific Research on Priority Areas (No. 277; 1996-98) administrated by the Ministry of Educa- tion, Science, Sports and Culture, Japan, which M.S. appreciates.

\section{REFERENCES}

1. For reviews, see: M. Szwarc, "Carbanions, Living Polymers and Electron-Transfer Processes," Interscience, New York, 1968; O. W. Webster, Science, 251, 887 (1991).

2. S. Nakahama and A. Hirao, Prog. Polym. Sci., 15, 299 (1990).

3. M. Miyamoto, M. Sawamoto, and T. Higashimura, Macromolecules, 17, 265, 2228 (1984).

4. M. Sawamoto and M. Kamigaito, in "New Methods of Polymer Synthesis," Vol. 2, J. R. Ebdon and G. C. Eastmond, Eds., Blackie, Glasgow, UK, 1995, p. 37.

5. H. Shohi, M. Sawamoto, and T. Higashimura, Polym. Bull., 25, 529 (1991).

6. H. Fukui, M. Sawamoto, and T. Higashimura, Macromolecules, 28, 3756 (1995).

7. S. Kanaoka, M. Sawamoto, and T. Higashimura, Macromolecules, 24, 5741 (1991).

8. H. Fukui, S. Yoshihashi, M. Sawamoto, and T. Higashimura, Macromolecules, 29, 1862 (1996).

9. S. Yoshihashi, M. Kamigaito, and M. Sawamoto, Polym. Prepr. Jpn., 45, 169 (1996)

10. K. Kitano, M. Kamigaito, and M. Sawamoto, Polym. Prepr: Jpn., 45, 169 (1996).

11. T. Hashimoto, H. Ibuki, M. Sawamoto, and T. Higashimura, J. Polym. Sci., Polym. Chem. Ed., 26, 3361 (1988).

12. K. Miyashita, M. Kamigaito, M. Sawamoto, and T. Higashimura, Macromolecules, 27, 1093 (1994).

13. H. Shohi, M. Sawamoto, and T. Higashimura, Macromolecules, 24, 4926 (1994).

14. N. Ise, T. Okubo, S. Kunugi, H. Matsuoka, K. Yamamoto, and Y. Ishii, J. Chem. Phys., 81, 3294 (1984).

15. T. Saegusa, Y. Chujo, K. Aoi, and M. Miyamoto, Makromol. Chem., Macromol. Symp., 32, 1 (1990). 